\title{
O endomarketing como elemento motivador: Estudo de caso do Banrisul
}

Daniela Gil

Analista de Marketing do Banrisul - Banco do Estado do Rio Grande do Sul. Bacharel em Comunicação Social - Relações Públicas pela Universidade Federal do Rio Grande do Sul- UFRGS Especialização em Comunicação Estratégica de Marketing - SENAC-RS. Cursando MBA em Gestão de Eventos - SENAC-RS.

E-mail: danigilcats@gmail.com

Recebido em: 7 junho 2018. Aceito: 05 julho. 2018.

DOI: http://dx.doi.org/10.21674/2448-0479.44.595-605

\section{Resumo}

Este artigo procura demonstrar a relevância do endomarketing nas organizações, tendo como objetivo descobrir qual a percepção dos funcionários sobre o endomarketing realizado pelo Banrisul. $\mathrm{O}$ colaborador satisfeito torna-se um verdadeiro "embaixador da marca", transmitindo, a partir de suas atitudes e informações, uma imagem favorável para os demais públicos da empresa. O estudo se embasou em referencial teórico sobre endomarketing, comunicação organizacional e gestão de pessoas. A coleta de dados foi realizada por meio um questionário estruturado encaminhado, via email interno, a todo o quadro da Direção Geral da empresa, obtendo respostas de 550 colaboradores, caracterizando uma amostra não probabilística, por conveniência. Contatou-se que os funcionários reconhecem ações de endomarketing realizadas pela empresa visando melhoria de sua qualidade de vida, principalmente no campo da saúde e educação. Entretanto, existe um trabalho de motivação a ser realizado pelo Banrisul, incrementando o feedback aos funcionários, priorizando um canal mais enxuto de informações e criando uma nova ferramenta onde os colaboradores possam emitir suas opiniões, sugestões e comentários à Instituição.

Palavras-chave: Endomarketing. Comunicação Organizacional. Gestão de Pessoas.

\section{Abstract The endomarketing as motivating element Banrisul case study}

This article seeks to demonstrate the relevance of internal marketing in organizations, aiming to find out what the perception of employees on internal marketing carried out by Banrisul. The satisfied employee becomes a true "brand ambassador", transmitting, from their attitudes and information, a favorable image to other stakeholders of the company. The study is based in part on theoretical framework on internal marketing, organizational communication and people management. The collection of data from this case study performed using a structured questionnaire sent, internal e-mail, the entire General Directorate of the company, getting answers of 550 employees, featuring a nonprobabilistic sample of convenience. It was not that employees recognize internal marketing actions 
taken by the company for improvement of their quality of life, especially in health and education. However, there is a motivation to work out by Banrisul, increasing the feedback to employees, emphasizing a more streamlined channel of information and creating a new tool where employees can send your opinions, suggestions and comments to the institution.

Keywords: Internal Marketing. Organizational Communication. People Management.

\section{Introdução}

O endomarketing utiliza as ferramentas do marketing no ambiente interno das organizações, buscando criar, através de uma comunicação integrada, a melhoria das relações interpessoais, da qualidade de vida e das estratégias de gestão.

Torna-se cada vez mais evidente a necessidade e a importância de se trabalhar o endomarketing dentro das empresas, pois a melhoria na comunicação interna motiva os funcionários, refletindo no desenvolvimento de suas atribuições, garantindo um melhor resultado final para o seu negócio (TAVARES, 2010). De acordo com Kunsch (2003, p.159), esta importância "reside, sobretudo, nas possibilidades que ela oferece de estímulo ao diálogo e à troca de informações entre a gestão executiva e a base operacional, na busca pela qualidade".

Ainda Tavares (2010, p.20) denomina dois enfoques básicos ao gerenciarmos o endomarketing: motivação e comunicação. A motivação é representada pelas atitudes dos funcionários: "[...] à medida que a empresa motiva o funcionário, ele está sempre mais proativo e desempenhando melhor suas tarefas". Já a comunicação interna é toda e qualquer divulgação de informações destinadas aos funcionários, e podem estar relacionados com as características de novos produtos, serviços, campanhas, mudanças no comportamento dos clientes em relação aos produtos e serviços da empresa, ações institucionais, informações sobre pesquisa, etc.

A partir destas premissas, e considerando o cenário do mercado financeiro atual, onde a qualidade do atendimento prestado é um dos maiores diferenciais entre os concorrentes, visualizouse como problema a ser compreendido: quais as ações de endomarketing estão sendo desenvolvidas pelo Banrisul, visando incrementar a motivação de seus colaboradores? Assim, estabelece-se como objetivo geral analisar qual a percepção dos funcionários sobre as ações de endomarketing que são desenvolvidas pelo Banrisul.

Este tema foi escolhido para estudo considerando que a comunicação com o público interno é um assunto desafiador quando realizado em uma instituição financeira. Poderá ainda trazer subsídios em relação à forma como o Banrisul gerencia seu endomarketing e desenvolve sua comunicação interna, tendo em vista ser uma organização de grande porte, e as dificuldades de comunicação que isso acarreta.

O artigo é apresentado em duas etapas. Em um primeiro momento, faz-se um levantamento teórico dos conceitos de endomarketing, sua relação com comunicação interna e motivação. Em seguida, fala-se da empresa e dos resultados da pesquisa aplicada aos seus funcionários. Estes resultados foram obtidos a partir de uma pesquisa quantitativa de caráter descritivo. Segundo Malhotra (2001), uma das razões para realizar uma pesquisa descritiva é para determinar as percepções sobre as características de produtos/serviços.

A partir da revisão teórica e da verificação das ações de endomarketing desenvolvidas pelo Banrisul foi elaborado um questionário estruturado, enviado via e-mail para todos os funcionários da Direção Geral da empresa, com o objetivo de descobrir sua percepção sobre o endomarketing 
realizado. A técnica de amostragem foi não probabilística, por conveniência. $E$ foi também bibliográfica, no que diz respeito aos referenciais teóricos sobre o assunto.

\section{Endomarketing}

Segundo Cerqueira (2005), os pioneiros no desenvolvimento de projetos de endomarketing foram os japoneses, e foi a partir da administração participativa que surgiram grandes projetos no mundo ocidental. Brum (1998) complementa citando que na década de 50, os japoneses demonstraram a importância do trabalho em grupo, ou seja, da reunião de pessoas em torno de um mesmo objetivo fazendo com que todos olhassem na mesma direção. Ela conceitua o endomarketing como forma de motivar os colaboradores através de programas internos. Para a autora, o melhor caminho para a motivação é a capacidade que algumas organizações têm de passar aos seus funcionários mensagens inspiradoras e coerentes, que os convençam a adotar uma atitude positiva em relação à empresa em que trabalham.

O endomarketing, porém, é mais que um novo conceito e sim uma nova postura de gestão, uma ferramenta que necessita uma abordagem diferenciada de mercado e de estrutura organizacional, havendo assim a necessidade de mudanças nas empresas (BEKIN, 1995). Concordando com o autor, Brum (1998) cita que "endo" provém do grego, que significa "ação interior", sendo assim, endomarketing significa marketing para dentro. Na mesma linha de pensamento, Bekin (2005, p.1) define o endomarketing como "ações de marketing para o público interno das empresas e organizações". Para ele, o endomarketing consiste em ações de marketing, voltadas para o público interno da empresa, tendo por objetivo promover entre seus funcionários e departamentos, valores destinados a servir o cliente externo. Cerqueira (2005) afirma que o endomarketing consiste num conjunto de processos, projetos ou veículos de comunicação integrada que permite a venda, ou seja, a consolidação de uma nova imagem para dentro da empresa.

Kunsch (2003), porém, critica a usabilidade do endomarketing, visto que acredita que o mesmo se limita a ver os colaboradores como clientes internos. A autora defende que o indivíduo, antes de ser empregado, é um ser humano e cidadão. É o que Bekin (1995), criador da terminologia endomarketing, afirma. Para ele, os funcionários devem ser tratados como clientes internos e valorizados como pessoas. Brum (1998) considera que o endomarketing tem por propósito fazer com que todos os colaboradores da empresa tenham uma visão compartilhada sobre a organização. Isto inclui metas, resultados, produtos e serviços. Segundo ela, o ser humano ocupa um lugar destacado na empresa e os resultados positivos nas organizações são provenientes da satisfação e motivação dos seus colaboradores. Assim, seu propósito é transformar o colaborador em facilitador para consolidar a imagem da empresa e o seu valor para o mercado. Seguindo o mesmo raciocínio, Bekin (1995, p.34) defende que o objetivo do endomarketing consiste em atrair e reter o funcionário visando obter resultados eficientes para a empresa, atraindo e retendo seus clientes externos. Segundo Cerqueira (2005), o endomarketing busca a criação de um clima ideal e a valorização e reconhecimento dos colaboradores, e com isso a obtenção de índices maiores de produtividade, qualidade e redução de custos.

Quanto à importância do endomarketing, Bekin (1995) acredita que do ponto de vista estratégico o Endomarketing é um processo com foco na adequação da empresa ao mercado orientado para o cliente. Desta forma, a relação da organização com o mercado passa a não ser apenas um serviço feito para os clientes externos, mas também para os clientes internos. $O$ autor defende que o resultado final para a empresa é tornar-se mais eficiente e mais competitiva. Andrade (2001, p.95) afirma que "posta a casa em ordem podemos depois mostrar a nossa fachada", ou seja, 
é prioritário que a organização trabalhe junto aos seus colaboradores, a fim de engajá-los, para depois desenvolver o marketing externo.

\section{Metodologia}

A pesquisa buscou analisar a percepção dos funcionários do Banrisul sobre as ações estratégicas de endomarketing desenvolvidos pelo Banrisul. Como técnica de coleta de dados deste estudo, foi utilizada pesquisa bibliográfica e pesquisa quantitativa, sendo que para esta a técnica de amostragem foi não probabilística, por conveniência. Segundo Malhotra (2001), uma das razões para realizar uma pesquisa descritiva é para determinar as percepções sobre as características de produtos e/ou serviços.

A pesquisa foi realizada com foco em um caso específico, caracterizando-a como um estudo de caso que para Yin (2001, p.20) "é o delineamento mais adequado do fenômeno contemporâneo dentro de seu contexto real". Os dados foram coletados através de questionário, elaborados e direcionados aos atores objetos da pesquisa, que opinaram sobre uma escala tipo likert de cinco pontos (discordo totalmente, discordo, não concordo nem discordo, concordo e concordo totalmente).

A partir da verificação das ações de endomarketing desenvolvidas pelo Banrisul foi elaborado um questionário estruturado, que foi encaminhado via e-mail para todo o quadro de funcionários da Direção Geral do Banrisul (2.984 colaboradores), sendo que destes 550 responderam (18,4\%). processamento dos dados do questionário foi organizado através de uma classificação ordenada, usando a escala tipo likert.

A pesquisa também pode ser considerada bibliográfica, pois na construção das referências teóricas deste trabalho foram consultados livros, artigos e dissertações, procurando obter conhecimento para descrever as teorias, no intuito de melhor desenvolver o tema abordado.

\section{O Banrisul}

O Banrisul é uma sociedade de economia mista, criado em 12 de setembro de 1928, e constituída como uma sociedade anônima, cujo maior acionista é o Estado do Rio Grande do Sul. Tem uma abrangência de $98,86 \%$ de participação no PIB do Estado e está presente em $86,32 \%$ dos municípios gaúchos. Como banco múltiplo, o Grupo Banrisul oferece ampla variedade de produtos e serviços financeiros, incluindo cartões de crédito, seguros, previdência privada, grupos de consórcios e administração de recursos de terceiros. Suas operações de crédito abrangem os segmentos de pessoas físicas e jurídicas, bem como financiamento imobiliário e rural. $\mathrm{Na}$ atuação social, dedica-se a fomentar projetos para melhorar a qualidade de vida dos gaúchos, principalmente, nas áreas da educação, cultura, esporte e meio ambiente.

Tabela 1 - O Banrisul em números

\begin{tabular}{c|c}
\hline Indicadores Estruturais & Dez 2014 \\
\hline Agências & 528 \\
\hline Postos de Atendimento Bancário & 206 \\
\hline Pontos de Atendimento Eletrônico & 594 \\
\hline Colaboradores & 11.636 \\
\hline \multicolumn{2}{c}{ Fonte: Site Banrisul (2015) }
\end{tabular}

O Banrisul define que sua missão é ser o agente financeiro do Estado para promover o desenvolvimento econômico e social do Rio Grande do Sul. Sua visão é ser um banco público, 
rentável, sólido e competitivo, integrado às comunidades a que presta serviços com excelência, seguindo os princípios e valores da transparência, ética, comprometimento, integração e eficácia.

A Direção-Geral é o conjunto dos órgãos administrativos diretamente subordinados à Diretoria ou ao Conselho de Administração, divididos de acordo com suas funções, conforme o organograma da empresa.

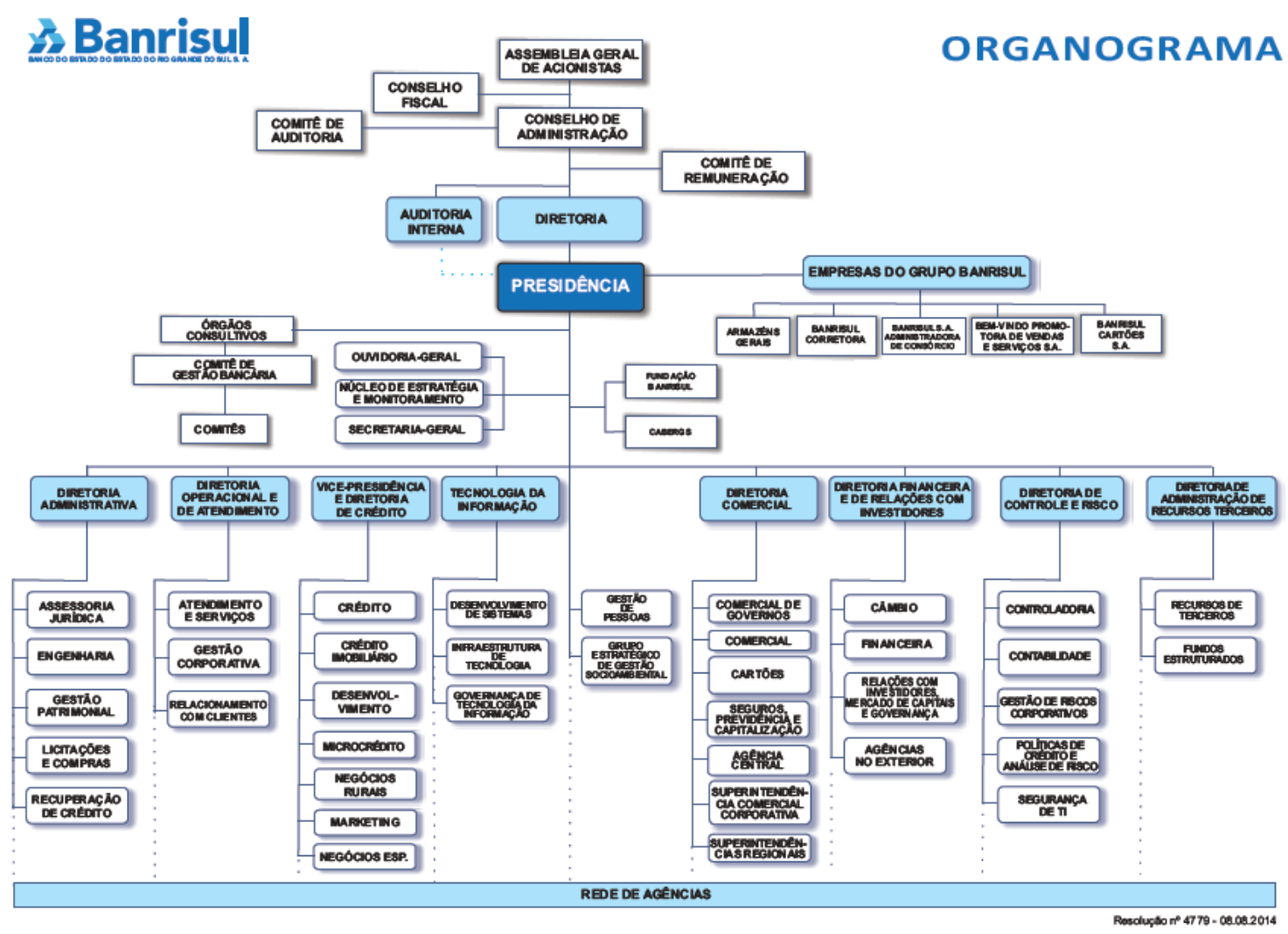

Figura 1 - Organograma Banrisul

Fonte: www.banrisul.com.br (2015)

\section{Análise e discussão dos resultados}

Brum (2010) defende que, quando o endomarketing é bem realizado, os funcionários tornamse pessoas mais criativas e felizes, capazes de surpreender, encantar e entusiasmar os clientes externos. Para criar este cenário são necessários três suportes: comunicação, empatia e relacionamento. Segundo a autora, criar um fluxo de informações é uma boa estratégia a ser desenvolvida para promover a aproximação dos colaboradores entre si e com a empresa. Portanto, a comunicação é o primeiro pilar do marketing interno. A empatia é o segundo pilar, sendo um atributo essencial para o líder, que deve ter a competência de gerir o relacionamento com o grupo. Essa empatia estimula a integração e o comprometimento dos colaboradores perante a organização. $\mathrm{O}$ terceiro pilar considerado por Brum (2010) é o relacionamento mútuo, que é obtido através de uma boa comunicação interna, que se for desenvolvida com clareza e transparência gera o bom relacionamento dos funcionários entre si e com a empresa.

A partir destas premissas foi elaborado o questionário aplicado aos colaboradores do Banrisul lotados na Direção Geral. Estes colaboradores oferecem suporte administrativo a toda rede de agências. Têm, portanto, como cliente de seus serviços, seus colegas de agências e de outras 
Unidades, que dependem da qualidade e presteza de seus serviços para melhor atender aos clientes do Banrisul.

Inicialmente traçou-se o perfil dos funcionários, que foi o seguinte: $29 \%$ possuem mais de 51 anos, $29 \%$ possuem entre 41 e 50 anos, $9 \%$ possuem entre 36 e 40 anos $16 \%$ possuem entre 31 e 35 anos, 14\% possuem entre 26 e 30 anos, e apenas $3 \%$ possuem entre 18 e 25 anos. Esta divisão etária se justifica pelo fato dos novos funcionários normalmente serem locados em agências, e ocorre uma migração para a Direção Geral ao longo da carreira. Com relação ao gênero, $60 \%$ são homens e $40 \%$ são mulheres.

Quanto à escolaridade, a grande maioria possui ensino superior completo $(36 \%)$ ou pósgraduação completa (32\%). Cursando ensino superior são $14 \%$, enquanto $8 \%$ estão fazendo uma pós-graduação. Com mestrado são $5 \%$, e com o ensino médio completo (requisito para ingresso no banco) são apenas 4\%. Este alto grau de escolaridade se explica pelo incentivo financeiro que o Banrisul oferece aos funcionários para frequentar cursos superiores, de pós-graduação e idiomas, desde que enquadrados dentro da área de atuação dos colaboradores. Para Dutra (2009), a preparação para o futuro exige investimentos tanto na modernização do sistema de gestão de pessoas como no estímulo e suporte ao desenvolvimento das pessoas por si próprias. $O$ autor ressalta que as empresas precisam de trabalhadores capacitados, que se atualizem continuamente.

Para avaliar o primeiro suporte citado por Brum (2010), a comunicação, perguntou-se sobre o conhecimento das metas e objetivos de sua Unidade e do Banco. As respostas obtidas foram as seguintes:

Tabela 2 - Comparativo de Conhecimento Metas Unidades/Metas Banrisul

\begin{tabular}{c|c|c}
\hline Conheço bem as Metas e Objetivos & Da Unidade & Do Banrisul \\
\hline Discordo Totalmente & $5 \%$ & $6 \%$ \\
\hline Discordo & $23 \%$ & $27 \%$ \\
\hline Não concordo nem discordo & $16 \%$ & $28 \%$ \\
\hline Concordo & $43 \%$ & $35 \%$ \\
\hline Concordo totalmente & $13 \%$ & $5 \%$ \\
\hline \multicolumn{2}{c}{ Fonte: Autora (2015) }
\end{tabular}

Fonte: Autora (2015)

Percebe-se que as metas das Unidades, que estão mais próximas do colaborador, são bem mais reconhecidas do que as da instituição. Isso mostra uma falha de comunicação, até porque as metas da Unidade devem estar relacionadas com as metas gerais da empresa. Outro dado que chama a atenção neste item é a grande migração para a resposta neutra. No caso de conhecimento, pode-se deduzir que a pessoa sabe ou não, no caso as metas e objetivos. Pode-se inferir, então, que os colaboradores não têm certeza de seu conhecimento, e optam pela neutralidade. As pessoas confundem a categoria neutra como "não sei" ou "não aplico", diz Akins (apud BATISTA, 2003). Segundo Bekin (1995), o endomarketing visa facilitar e realizar trocas construindo relacionamentos com os funcionários, compartilhando os objetivos da empresa ou organização, harmonizando e fortalecendo estas relações. Portanto, é fundamental que todos os colaboradores tenham bem claros quais os objetivos e metas, tanto de sua Unidade quanto do Banrisul, para que possam se empenhar em suas conquistas. De acordo com Dias (2008), é importante a organização ter a visão, a missão e os objetivos estratégicos bem definidos para seus empregados, pois assim eles se comprometem mais com a organização na conquista dos objetivos definidos.

O mesmo aconteceu ao serem questionados sobre a existência de um canal para o empregado comunicar opiniões, dúvidas, sugestões e reclamações à empresa. A grande maioria (47\%) discorda (sendo que $14 \%$ totalmente). Concordam com a afirmação $22 \%$, sendo que destes apenas $2 \%$ concordam totalmente. E $31 \%$ não concordam nem discordam, o que permite concluir que 
não conhecem os canais de comunicação existentes com a empresa. O Banrisul disponibiliza um canal de comunicação para que seus colaboradores informem indícios e/ou suspeitas de irregularidades, bem como práticas ilícitas identificadas no ambiente da organização. Para sugestões ou feedback para a administração não existe um canal específico, apenas o Fórum de Discussões . Quando uma organização possui fluxos de informação bem desenhados, os funcionários se comunicam de forma contínua e informal entre si e com seus superiores. Assim, todos os funcionários, independentemente da hierarquia, formam uma imagem positiva da empresa em que trabalham.

Quando perguntados se as informações internas estão disponibilizadas de forma clara e acessível, 54\% concordam, e 26\% discordam. Como $20 \%$ não concorda nem discorda, pressupõe-se novamente que desconheçam os canais de informação. Kunsch (2003) ressalta que é relevante se ter uma comunicação interna participativa, por meio de todo o instrumental disponível, envolvendo o empregado nos assuntos da organização e nos fatos que estão ocorrendo no país e no mundo, desta maneira ele acompanhará de forma consciente a dinâmica da história, sendo considerado mais que um número frente aos outros funcionários, mas sim alguém que exerce suas funções em parceira com a organização e em sintonia com a realidade social vigente.

Ainda no tema da comunicação interna, questionou-se qual a ferramenta de comunicação interna era a mais utilizada pelos colaboradores. As respostas foram as seguintes:

Tabela 3 - Utilização de Ferramentas de Comunicação Interna no Banrisul

\begin{tabular}{|c|c|}
\hline Ferramenta Comunicação Interna & $\%$ \\
\hline $\begin{array}{l}\text { Intranet (reúne todos os canais de informação sobre produtos, treinamento, campanhas, mercado, } \\
\text { metas, taxas, patrocínios, serviço) }\end{array}$ & $90,0 \%$ \\
\hline E-mails & $90,0 \%$ \\
\hline $\begin{array}{l}\text { Minuto-a-Minuto (apresenta informações internas do banco (instruções comerciais, administrativas, } \\
\text { resoluções da diretoria, oportunidades) com atualização instantânea) }\end{array}$ & $48,5 \%$ \\
\hline $\begin{array}{l}\text { Informações Normatizadas- IN (toda a normatização do banco. Toda a rotina operacional possui } \\
\text { sua IN, com o detalhamento de todas as suas funções) }\end{array}$ & $40,2 \%$ \\
\hline $\begin{array}{l}\text { Sinopse Diária (clipping de notícias sobre o Banrisul encaminhado via e-mail pela Assessoria de } \\
\text { Imprensa) }\end{array}$ & $26,5 \%$ \\
\hline $\begin{array}{l}\text { Biblioteca Digital (contém diversos manuais e passo-a-passo de todo o operacional dentro do } \\
\text { banco -engloba as INs, revista on-line, campanhas, atas, etc...) }\end{array}$ & $26,0 \%$ \\
\hline Reuniões de Equipe & $25,5 \%$ \\
\hline $\begin{array}{l}\text { Info Rede (canal onde são armazenadas as Instruções Comerciais e o FAQ (Perguntas Frequentes). } \\
\text { As instruções comerciais são mensagens relacionadas a novos negócios e sua operacionalidade, e o } \\
\text { FAQ apresenta as dúvidas dos funcionários, respondidas pelo setor responsável) }\end{array}$ & $24,5 \%$ \\
\hline Banrinews (newsletter semanal) & $21,8 \%$ \\
\hline Mural & $19,1 \%$ \\
\hline $\begin{array}{l}\text { Site Comercial (apresenta campanhas de vendas de produtos, relação dos vencedores e fotos da } \\
\text { entrega de premiações. Apresenta também parciais de venda por funcionário e agência). }\end{array}$ & $16,9 \%$ \\
\hline $\begin{array}{l}\text { Bom dia (apresenta as taxas, juros e prazos máximos de todos os produtos. Atualizada } \\
\text { constantemente, deve ser consultada a cada operação de crédito) }\end{array}$ & $14,5 \%$ \\
\hline $\begin{array}{l}\text { Revista Perspectiva e Percepções (impressa, distribuída aos funcionários. Trata de assuntos } \\
\text { diversos: treinamentos, sustentabilidade, projetos sociais apoiados, etc.) }\end{array}$ & $14,2 \%$ \\
\hline $\begin{array}{l}\text { CA Online (ferramenta de pesquisa, com informações sucintas sobre operacionalidades da agência e } \\
\text { auxilia a localizar informações mais detalhadas) }\end{array}$ & $10,5 \%$ \\
\hline $\begin{array}{l}\text { Com você (ferramenta audiovisual onde uma professora virtual apresenta produtos, resultados e } \\
\text { metas, e ainda orienta sobre melhores técnicas de venda) }\end{array}$ & $7,6 \%$ \\
\hline
\end{tabular}

Segundo Brum (2003) a organização precisa de um canal de comunicação interna que centralize as informações da empresa, contendo informações recentes e uma veiculação sistemática, 
como no caso de uma intranet corporativa, onde a informação possa ser utilizada como estratégia de aproximação com o empregado. Constatou-se que o Banrisul centraliza quase todas as suas ferramentas na intranet. Contudo, existe uma grande queixa dos funcionários sobre o excesso de canais, e a falta de clareza de que tipo de informação está em cada um, fazendo com que se perca muito tempo tentando localizar a informação desejada.

A comunicação interna, aos olhos de Brum (2010, p.35), é "a comunicação entre empresa/empregado". E acrescenta: "É a informação decorrente de uma decisão que deve sair da parte de cima da pirâmide e descer até a base". Para Kunsch (2003), no entanto, a comunicação interna não é simplesmente uma transmissão de informações e sim um setor planejado, com objetivos definidos, para viabilizar toda e qualquer interação possível entre a organização e seus empregados. Sendo assim, a comunicação interna corre paralelamente com a circulação normal da comunicação que perpassa os setores da organização, permitindo seu pleno funcionamento. São os instrumentos de comunicação interna que, pela sua eficiência e aceitação, transformam-se em canais oficiais dentro da empresa, aderindo à rotina da instituição e despertando no público interno a política de entendimento e participação dos assuntos, tanto internos, quanto externos, e educando as pessoas para o aprendizado, tanto a partir da leitura, quanto da observação.

Outro ponto que foi levantado junto aos entrevistados foi se as informações sobre a empresa (institucionais, lançamento de produtos e serviços, etc.) são repassadas aos funcionários antes da divulgação ao público externo: 50\% discordaram (sendo que 10\% discordou totalmente), enquanto $26 \%$ concordaram com a afirmação. Brum (1998) comenta que a motivação dos funcionários não é apenas receber salários altos, eles precisam sentir que fazem parte da empresa. Informá-los adequada e claramente sobre acontecimentos, mudanças e negócios, ressaltando que sem a colaboração conjunta não será obtido sucesso, é imprescindível para que os colaboradores se sintam parte integrante da empresa.

Ao questionar sobre se existe uma boa comunicação entre as Unidades, 57\% discordaram (sendo que 13\% totalmente). Apenas 18\% concordaram, e 23\% mantiveram-se neutro. Entende-se que ao implantar um plano de endomarketing na empresa, as unidades devam estar interligadas para que a comunicação aconteça de maneira eficiente. Essa comunicação gerenciada propõe aos funcionários maior liberdade nos processos de tomada de decisão, trazendo uma maior motivação no desenvolvimento de suas atribuições. Bekin (1995) acredita que o objetivo do endomarketing é fazer com que os departamentos e os funcionários de uma organização compartilhem de valores e objetivos, e para isso apropria-se de um processo de coesão e comunicação interna no ambiente organizacional.

Quando questionados se existem programas contínuos de treinamento na empresa, $41 \%$ dos entrevistados concordam, $21 \%$ não concordam nem discordam, 24\% discordam, $8 \%$ discordam totalmente e 6\% concordam totalmente. Como desde abril de 2013, a instituição conta com o programa de Educação à Distância (EAD), visando facilitar o desenvolvimento dos funcionários sem a necessidade de deslocamento do seu local de moradia e de trabalho, justifica-se o grande reconhecimento por parte dos funcionários entrevistados. E, numa evolução deste programa de treinamento, o Banrisul criou sua própria universidade corporativa, na qual qualquer pessoa, sendo ou não cliente da instituição, poderá fazer cursos on-line sobre diferentes assuntos a partir do primeiro trimestre de 2015. Segundo Chiavenato (2004), o capital humano depende de talentos que a empresa precisa conquistar, desenvolver, motivar e recompensar, para ser competitiva. E o Banrisul possui vários programas de incentivo para seus funcionários, que recebem apoio financeiro da empresa para cursar idiomas, cursos, graduação e pós-graduação. 
Procurando avaliar o segundo pilar citado por Brum (2010), a empatia, foi questionado se os funcionários recebem feedback das atividades desenvolvidas na empresa: $42 \%$ afirmam não receber, $33 \%$ recebem e $25 \%$ manteve-se neutro. Como o retorno deve ser dado pela chefia direta, isso varia de gestor para gestor. Segundo Brum (2003) os funcionários e as empresas muitas vezes possuem grande dificuldade para se comunicar, por isso a importância de saber dar e receber constantemente feedback, num estímulo constante ao relacionamento aberto, transparente e sadio. A autora afirma que a motivação é possível de ocorrer na empresa por meio de procedimentos simples, como dar aos funcionários as informações necessárias para a realização de um bom trabalho, cumprimentá-lo pessoalmente por uma tarefa bem feita, enviar-lhe uma mensagem escrita elogiando 0 seu desempenho, solicitar suas ideias, mostrando o quanto são importantes para a empresa, envolve-lo nas questões e decisões relacionadas com o seu trabalho e com a sua área de atuação, etc. Todos devem entender o quê e porquê estão fazendo e como seus resultados se relacionam aos dos outros e aos objetivos gerais da empresa. Segundo Bekin (2005) comunicação é informação com feedback. O autor acrescenta que para motivar o funcionário se faz necessário o reconhecimento pelo trabalho realizado, reconhecimento pela sua importância como individuo dentro da empresa, além de remuneração adequada e possibilidade de avanço profissional.

Para verificar o terceiro pilar citado por Brum (2010), o relacionamento mútuo, questionou-se aos funcionários se são valorizados pela empresa: $54 \%$ discordam (sendo que $22 \%$ totalmente). Apenas $23 \%$ concordam, e $23 \%$ não concordam nem discordam. O sentimento de desvalorização gera uma profunda desmotivação no grupo funcional. Motivar pessoas e atingir elevados padrões de desempenho organizacional é hoje uma questão de sobrevivência das organizações em um mundo de negócios altamente mutável e competitivo. A competitividade externa depende basicamente da cooperação e colaborações internas (CHIAVENATO, 2005). Complementa Robbins (2002), citando que todas as pessoas podem ser motivadas, visto que a motivação é o resultado da interação do indivíduo com a situação. Contudo, são os programas de endomarketing os responsáveis por colocar em prática a constante preocupação da organização estudada em tornar seus funcionários motivados, com a devida intensidade, direção e persistência.

Para finalizar a pesquisa, foi questionado se o colaborador sentia que o Banrisul se preocupava em auxiliá-lo na busca de uma boa qualidade de vida: $42 \%$ concordam com a afirmação, enquanto $28 \%$ discordam. $31 \%$ mantiveram-se neutros, não concordando nem discordando. Esta percepção favorável é justificada pelo fato do Banrisul oferecer aos funcionários vários programas que visam incentivar os cuidados com a saúde entre seus funcionários: Banribike, Banrirunners, Grupo de Caminhada e Ginástica Laboral. Destaca-se também o trabalho de conscientização feito pelo Socioambiental sobre descarte correto do lixo, de pilhas e lixo eletrônico, o incentivo à doação de sangue e ao voluntariado, tudo visando conscientizar o colaborador da importância das atitudes individuais no resultado coletivo. Possui, também, além do apoio financeiro para cursos de graduação, pós-graduação e idiomas, diversos cursos EAD e Universidade Corporativa. Os funcionários gozam também de isenção de tarifas e taxas especiais em operações de crédito. Kunsch (2003) defende que o indivíduo, antes de ser empregado, é um ser humano e cidadão.

\section{Considerações finais}

O cenário bancário atual, altamente competitivo, exige que as organizações busquem diferenciais, sendo que o atendimento prestado por seus funcionários é um dos mais decisivos. Este trabalho teve por tema de estudo o endomarketing, apresentando dados teóricos e práticos sobre o 
tema referido. Por meio de revisão bibliográfica e da realização de pesquisa quantitativa, obteve-se a comunhão entre teoria e prática, resultando na contribuição que este estudo ofereceu para a compreensão dos fenômenos que se apresentam no Banrisul, tendo como foco a motivação e o comprometimento dos colaboradores dentro de um ambiente empresarial. $\mathrm{O}$ objetivo deste trabalho foi responder ao seguinte questionamento: qual a percepção dos funcionários do Banrisul sobre o endomarketing realizado pela empresa?

Este estudo demonstrou que o uso estratégico do endomarketing ainda é incipiente no Banrisul, percebendo-se, porém, uma preocupação da empresa com seu capital intelectual, com investimentos constantes em seu quadro funcional. Constatou-se que existe o reconhecimento de que a empresa presta informações de modo acessível e claro aos funcionários, mas de uma maneira desorganizada.

Em relação à motivação obtida a partir do endomarketing do Banrisul, constatou-se que este processo está sendo desenvolvido, mas não foi totalmente percebido pelos funcionários. Com base nos dados da pesquisa constata-se que os colaboradores não estão satisfeitos com o fluxo de comunicação entre as Unidades, e que sentem falta de um canal para expressar suas opiniões e sugestões à empresa. Verificou-se também que os funcionários não estão sentindo-se suficientemente valorizados, o que poderia ser revertido com a criação de uma ferramenta onde os funcionários interajam com a administração, recebendo um retorno direto da mesma.

Para Bekin (2005) não há mágicas para bons resultados em endomarketing, apenas objetivos bem definidos, claramente divulgados e mobilização interna para o alcance destas metas. $O$ autor cita que umas das habilidades que a empresa precisa ter é a capacidade interna de alinhar pessoas e processos aos objetivos do negócio. A comunicação interna, quando bem realizada, cria um clima favorável na organização, o que proporciona um bom ambiente de trabalho, que motiva os colaboradores. A partir deste estudo, destaca-se a importância de que sejam reorganizados os canais de comunicação interna, tornando a busca de informação mais ágil; e a criação de um canal direto para os funcionários manifestarem-se junto aos gestores. Segundo Carvalho (2010), o endomarketing deve ser gerido por profissionais de marketing, que possuem competência para trabalhar com os diversos públicos.

Constatou-se como limitação a este trabalho o campo restrito de pesquisa, apenas os funcionários da Direção Geral, que constituem $25,6 \%$ do quadro funcional. Assim, como possibilidade para estudos futuros, o Banrisul poderia estender esta pesquisa para a rede de agências, tendo um cenário real sobre a percepção de todos os seus funcionários sobre o endomarketing realizado.

\section{Referências}

ANDRADE, T. Para entender Relações Públicas. 3. ed. São Paulo: Loyola, 2001.

BANRISUL. Banco do Estado do Rio Grande do Sul. [Site institucional]. Disponível em <http://www.banrisul.com.br>. Acesso em: 15 dez. 2014.

BATISTA, M. J. Análise do número de categorias da escala de Likert aplicada à gestão pela qualidade total através da teoria da resposta ao item. [2003]. Disponível em: <http://www.abepro.org.br/biblioteca/enegep2003_tr0201_0741.pdf>. Acesso em 20 jan. 2015.

BEKIN, S. F. Endomarketing: como praticá-lo com sucesso. São Paulo: Pearson, 2005.

Conversando sobre endomarketing. São Paulo: Makron Books, 1995. 
BRUM. A. de M. Endomarketing de A a Z: como alinhar o pensamento das pessoas à estratégia da empresa. São Paulo: Integrare Editora, 2010.

Respirando Endomarketing. Porto Alegre: LP\&M, 2003. $\overline{L \& P M}, 1998$.

Endomarketing como Estratégia de Gestão: encante seu cliente Interno. Porto Alegre:

CARVALHO, L. C. Endomarketing em nova perspectiva. [2010]. Disponível em:<http://casesdesucesso.wordpress.com/2010/04/06/endomarketing-em-nova-perspectiva/>.

Acesso em: 08 dez. 2014.

CERQUEIRA, W. Endomarketing: educação e cultura para a qualidade. 4. ed. Rio de Janeiro: Qualitymark, 2005.

CHIAVENATO, I. Gestão de pessoas: o novo papel dos recursos humanos nas organizações. 2. ed. Rio de Janeiro: Elservier, 2004.

Comportamento Organizacional: a dinâmica do sucesso das organizações. 2. ed. Rio de Janeiro: Elsevier, 2005.

DIAS, J. G. G. Endomarketing: um instrumento estratégico na busca da melhoria da competitividade empresarial. São Paulo: Livro Pronto, 2008.

DUTRA, J. S. Gestão de Pessoas: modelo, processos, tendências e perspectivas. São Paulo: Atlas, 2009.

KUNSCH, M. M. K. (Org.). Obtendo resultados com relações públicas. 2. ed. São Paulo, SP: Pioneira Thomson Learning, 2006.

Planejamento de Relações Públicas na Comunicação Integrada. 4. ed. São Paulo: Summus, 2003.

MALHOTRA, N. K. Pesquisa de Marketing: uma orientação aplicada. 3. ed. Porto Alegre: Bookman, 2001.

ROBBINS, S. P. Comportamento Organizacional. São Paulo: Prentice Hall, 2002.

TAVARES, M. Comunicação empresarial e planos de comunicação: integrando teoria e pratica. 3 . ed. São Paulo: Atlas, 2010.

YIN, R. Estudo de caso: planejamento e métodos. Porto Alegre: Bookman, 2001. 